\title{
Autoimmune cerebellar ataxia associated with anti-Purkinje cells antibodies: the next frontier of neuroimmunology
}

\author{
Weihua Zhang ${ }^{1 \#}$, Haitao Ren ${ }^{2 \#}$, Xiaotun Ren ${ }^{1}$, Fang Fang ${ }^{1 *}$, Hongzhi Guan ${ }^{2 *}$ \\ ${ }^{1}$ Department of Neurology, Beijing Children's Hospital, Capital Medical University, National Centre for Children's Health, Beijing, China; \\ ${ }^{2}$ Department of Neurology, Peking Union Medical College Hospital, Chinese Academy of Medical Sciences and Peking Union Medical College, \\ Beijing, China \\ Contributions: (I) Conception and design: F Fang, H Guan; (II) Administrative support: None; (III) Provision of study materials or patients: None; \\ (IV) Collection and assembly of data: None; (V) Data analysis and interpretation: None; (VI) Manuscript writing: All authors; (VII) Final approval of \\ manuscript: All authors. \\ \#These authors contributed equally to this work. \\ *These authors contributed equally to this work. \\ Correspondence to: Fang Fang. Department of Neurology, Beijing Children's Hospital, Capital Medical University, National Centre for Children's \\ Health, Beijing, China. Email: 13910150389@163.com; Hongzhi Guan. Department of Neurology, Peking Union Medical College Hospital, \\ Chinese Academy of Medical Sciences and Peking Union Medical College, Beijing, China. Email: pumchghz@126.com.
}

\begin{abstract}
Autoimmune cerebellar ataxia (ACA) is an important cause of sporadic cerebellar ataxia. Technological innovation promotes the rapid development of cerebellar autoimmunity researches in recent years. More and more new antibodies have been proposed to be associated with ACA. Several autoantibodies against Purkinje cells (PCs) have been identified, which constitute the main components. These autoantigens are mainly located in the cytoplasm and dendrites of PCs, and exhibit a specific morphology in immunohistochemistry (IHC). Although the clinical features are relatively homogeneous, there were still some differences among different antibodies. Due to the lack of understanding of the disease and the limited detection technology, it is really difficult to diagnose and manage at present. However, unlike the most of hereditary ataxias, ACA is treatable, and even the neurological dysfunction of some patients may be reversible. Therefore, promptly identification, diagnosis and treatment may benefit some patients. Thus, this article elaborates on the clinical manifestations and laboratory characteristics of anti-PCs-antibodyassociated ACA in order to help neurologists to understand ACA more comprehensively. At the same time, combining our previous exploratory work as well as the technology available, we try to propose a diagnostic strategy for ACA the text and the relevant differential diagnosis was illustrated in detail.
\end{abstract}

Keywords: Autoimmune cerebellar ataxia (ACA); purkinje cell (PC); antibody; paraneoplastic cerebellar degeneration (PCD)

Submitted Mar 04, 2020. Accepted for publication Jul 02, 2021. Published online Jul 21, 2021.

doi: $10.21037 /$ atm-20-2187

View this article at: https://dx.doi.org/10.21037/atm-20-2187

\section{Introduction}

Autoimmune cerebellar ataxia (ACA) is also known as immune-mediated cerebellar ataxia (IMCA). Generally, it refers to the cerebellum and related structural dysfunction caused by various autoimmunity disorders such as opsoclonus-myoclonus syndrome (OMS), Miller Fisher Syndrome, and Central Nervous System (CNS) demyelinating disease (1). An etiological study with a sample size of 1,500 showed that autoimmunity accounted for more than $50 \%$ of sporadic cerebellar ataxias (2). In the previous two decades, with the discovery of new antineural antibodies, an increasing number of antibodies have been confirmed to be related to ACA (antibodyrelated ACA). Although many antibodies do not seem to 
be directly pathogenic, they probably exist as markers of a particular autoimmune process in the CNS, which may imply autoimmune attribute and can provide a basis for considering immunotherapy.

There are three classification systems for these antibodies. First, according to whether antibodies are related to neoplasms, they are divided into paraneoplastic antibodies and non-paraneoplastic antibodies. Second, depending on where the antigen-antibody binds on the cell, they are classified into three groups including anti-nuclear and cytoplasmic proteins antibody, anti-cell surface protein antibody, and anti-intracellular synaptic antigen antibody (3). The third is based on specific binding targets, and these targets include Purkinje cells (PCs), molecular and granular layers, pinceau formation/basket cells, oligodendrocytes, and neuronal nuclei and nucleoli (4). Anti-PCs antibodies are the most important group. The clinical significance and laboratory characteristics of anti-PCs-antibodies associated with ACA (anti-PCs-ACA) is the subject of interest in this article.

\section{History and background}

The understanding of anti-PCs-ACA begins with paraneoplastic cerebellar degeneration (PCD), which is the most common phenotype in paraneoplastic neurological syndrome (PNS). Anti-PCs-ACA mainly manifests as progressive cerebellar-brainstem dysfunction, including ataxia, nystagmus, dysarthria, dysmetria, and vertigo. Cerebellar atrophy with destruction of PCs and related cells was found in histology (5). In 1976, Trotter identified antiPC antibodies in a patient with PCD and Hodgkin's disease (HD) (6). Subsequently, Greenlee and Brashear detected the same antibodies in the serum of two patients with PCD associated with ovarian carcinoma in 1983. These antibodies did not react with antigens from other tissues and were not found in the serum of controls. However, postmortem examination revealed an extensive loss of PCs (5). These studies strongly support the autoimmunity-related mechanism in PCD, and that PCs are the main targets of the autoimmunity process. After that, other antibodies are identified successively such as, anti-Yo, anti-Tr, antimicrotubule-associated protein (MAP) 1B/anti-Purkinje cell cytoplasmic antibody 2 (PCA-2), anti-Homer, and antiprotein kinase $\mathrm{C}$ gamma $(\mathrm{PKC} \gamma)$. With further research, some anti-PCs antibodies were found in patients without tumors (non-PCD/ataxia) such as anti-neurochondrin (NCDN) antibody. Although different antibodies have different binding patterns in immunohistochemistry (IHC), they mainly bind to soma and dendrites of PCs; thus, when stained using cerebellar tissue sections, the morphology is similar to the 'Gorgon head'. This is why they are often referred to as 'Medusa head' antibodies. Therefore, these antibody-related ataxias are called as Medusa head ataxias by some researchers $(4,7,8)$. The pathogenicity of antibodies is controversial. Anti-PCs antibodies belong to intracellular antibodies and T-cell-mediated mechanisms might be responsible. Therefore, most researchers believe that they lack direct pathogenicity but exist as markers (3).

\section{Laboratory and clinical characteristics of anti-PCs-antibodies}

The binding antigens of anti-PCs-antibodies are intracellular proteins, which are mainly distributed in the cytoplasm and dendrites. Compared with anti-cell surface protein antibodies, the pathogenic mechanism of these antigens is uncertain. Most patients present with chronic courses. Some patients respond poorly to immunotherapy. So far, more than ten kinds of anti-PCs-antibodies have been identified (Table 1). Due to different binding antigens, their binding patterns are specific. Experienced examiner can even roughly identify specific morphology, in tissue-based assay (TBA) stained smear. In addition, although the symptoms of cerebellar ataxia may be similar, there are some differences in many aspects such as onset characteristics, onset age, tumor occurrence, treatment effect, just to name a few.

\section{Anti-Yo/anti-Purkinje cell cytoplasmic antibody 1 (PCA-1) antibody}

There are two types of Yo antigens, cerebellar degenerationrelated 2 (CDR2) and CDR3 $(39,40)$. Their binding is mainly restricted to the cerebellum and brainstem. Greenley and Brashear first identified high-titer anti-Yo antibodies in patients with PCD in 1983 (5). IHC showed that the cytoplasm of the PC somata was stained in a typical coarse, granular pattern and nucleus spared. The peripheral PC dendritic branches can be weakly observed $(5,41)$ (Figure $1 \mathrm{~A}$ showed the IHC of serum anti-Yo antibody, versus the negative control shown in Figure 1B). However, no axonal staining was observed. We previously used the rat cerebellum tissue section as the matrix to detect anti-Yo antibody by IHC and indirect immunofluorescence in our lab. At present, the immunoblotting membrane coating with recombinant Yo antigen is more objective and convenient (9). Although 
Table 1 Characteristics of anti-PCs antibodies

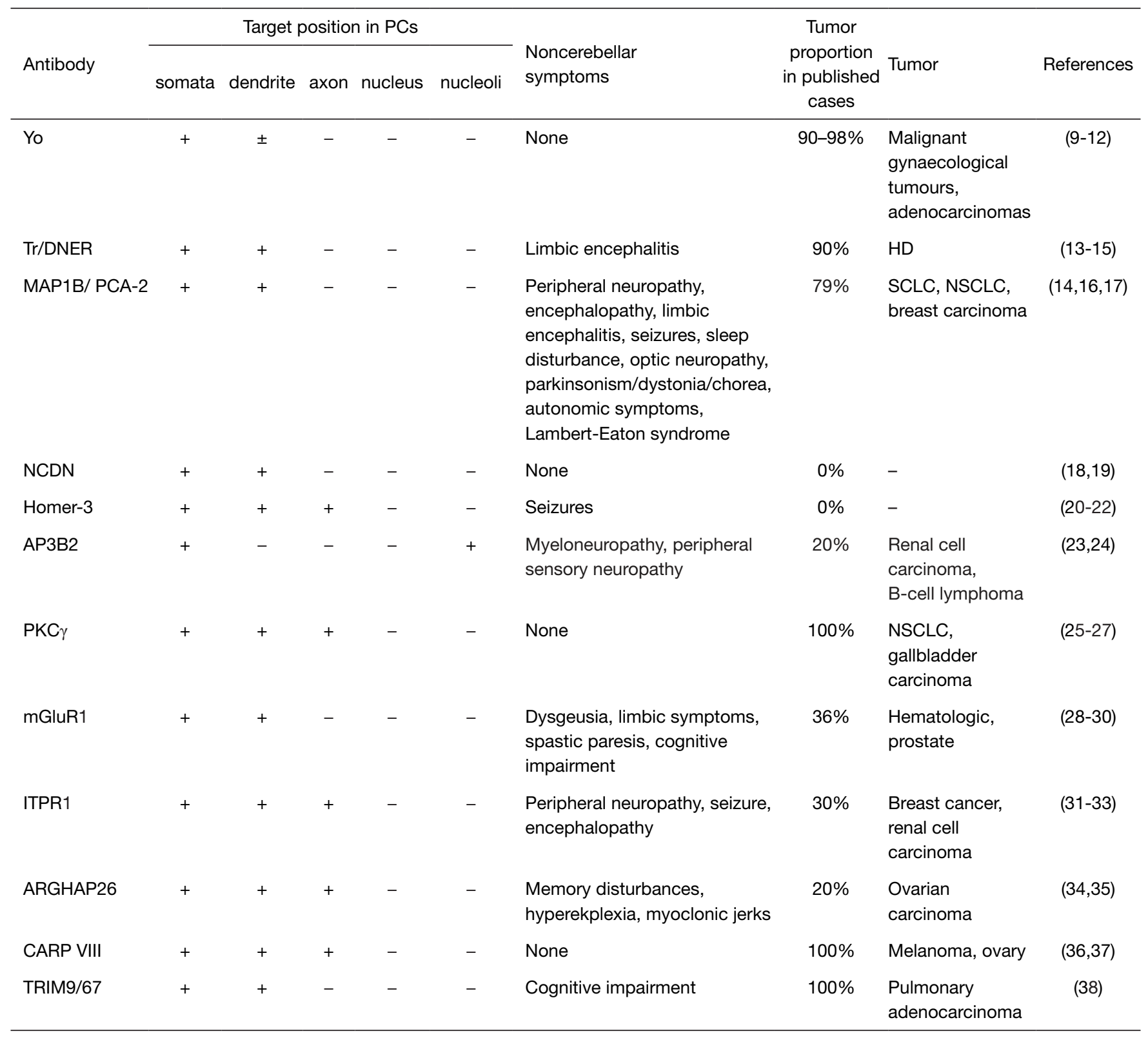

PCs, Purkinje cells; DNER, related receptor; HD, Hodgkin's disease; MAP1B/PCA-2, microtubule-associated protein 1B/Purkinje cell cytoplasmic antibody 2; SCLC, small cell lung carcinoma; NSCLC, non-small cell lung carcinoma; NCDN, neurochondrin; PKC $\gamma$, protein kinase C gamma; mGluR1, metabotropic glutamate receptor 1; ITPR1, inositol 1,4,5-trisphosphate receptor type 1.

previous studies have verified intrathecal IgG synthesis, the proportion of positive Yo-antibodies in cerebrospinal fluid (CSF) in our study is lower than that in serum. However, we have also observed that serum anti-Yo antibodies continue to be positive after tumor removal and immunotherapy, suggesting that persistent peripheral production of the antibody (9). This mechanism needs further study for clarification.

Anti-Yo antibodies are the most frequent PCD-related antibodies, accounting for about half of all PCDs. Cancer was detected in $90 \%$ to $98 \%$ of patients with cerebellar ataxia with anti-Yo antibody positivity. Breast and pelvic cancers are more common than lung cancers, and adenocarcinomas of the prostate and gastrointestinal system have been reported 

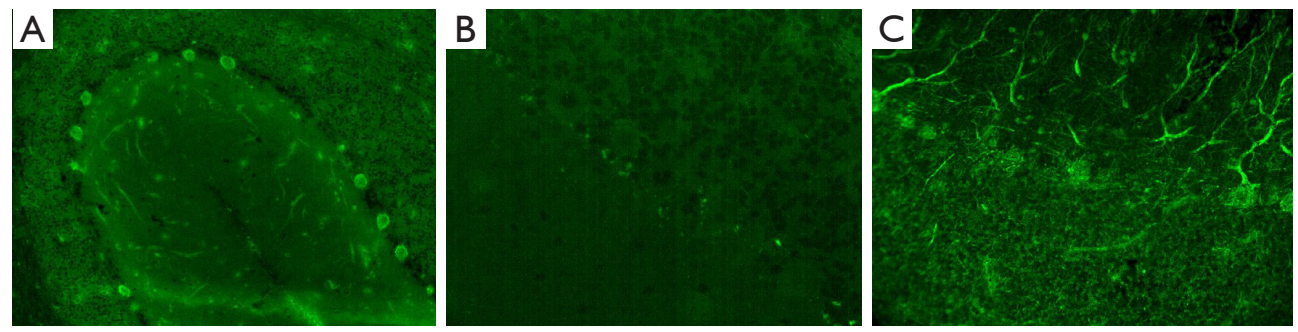

Figure 1 Immunofluorescence. (A) Binding of serum anti-Yo antibody from the patient to monkey cerebellum tissue sections ( $\times 200)$; (B) negative control (serum from other neurological patients) $(\times 200)$; (C) binding of serum anti-Homer-3 antibody from the patient to monkey cerebellum tissue sections $(\times 200)$.

in a few cases (9-11). Anti-Yo-PCD presents with subacute symptoms of progressive cerebellar impairment, most of which gradually progress within weeks to months. Truncal and limb ataxia, dysarthria, and nystagmus are the most common symptoms. In the early stage, ataxia may appear asymmetric. Rare symptoms such as long-tract involvement, diplopia, peripheral neuropathy, cognitive impairment, dysphagia, and vertigo, have been reported occasionally (12). CSF pleocytosis, protein elevation, and/or oligoclonal bands (OCBs) were found in 83-96\% of patients. Cranial magnetic resonance imaging (MRI) may be normal in the early phase, and cerebellar atrophy usually appears after the disease is well established (11).

Tumor treatment includes surgical resection of tumors, radiotherapy, and chemotherapy; however, most of them are ineffective. Immunotherapies including corticosteroids, intravenous immunoglobulin (IVIG), and plasma exchange (PLEX) are probably ineffective. Currently, there is no evidence-based guideline on treatment. Both functional and survival outcomes were poor. The proportion of chairbound is $77-94 \%$ at plateau phase $(10,11)$.

\section{Anti-Tr/delta notch-like epidermal growth factor (EGF)-related receptor (DNER) antibody}

DNER is the target antigen of anti-Tr antibody, which was first identified in a 21-year-old woman with subacute PCD and HD by Trotter (6). The reactivity was, therefore, later named anti-Tr (for Trotter) (13). DNER is a single-pass type I transmembrane protein that is highly expressed in cytoplasm and dendrites of PCs as well as in some pyramidal neurons found in the hippocampus and the cortex in mice $(42,43)$. PC axons are usually spared (44). PCs were stained in a punctuate somatodendritic manner in rat brain sections $(42,43,45)$. In addition to IHC, immunocytochemistry (ICC) employing primary hippocampal neurons and western blot has been used to demonstrate anti-Tr seropositivity $(42,46)$. In 2015, Probst's team confirmed that the sensitivity of recombinant cell-based indirect immunofluorescence assay (RC-IFA) for anti-Tr antibodies is $100 \%$ (95\% CI; $92.8-100 \%)$ and the specificity was $100 \%$ (95\% CI; 98.7-100\%) (47). Anti-Tr-PCD accounts for $14 \%$ of all PCD cases $(13,48)$. Approximately 30 cases have been reported. In 2019 and 2020 , our team reported three cases $(14,15)$. None of them had cancer, and all three of them were female. The average age at disease onset is 61 years $(14,15)$ and some cases in children have been reported $(13,49)$. It has been reported that $89 \%$ of anti-Tr-PCDs suffer from HD, and the sex ratio of men and women is $3: 1(13,49)$, which is different from the above-mentioned data in China. Acute or subacute onset presents mainly as axial and limb ataxia in most cases, which attains the plateau phase in a few months. Cranial MRI is usually normal at onset, but cerebellar atrophy appears in later stages. CSF pleocytosis was found in $60 \%$ of patients. A case series study of anti-Tr antibody related cerebellar ataxia showed that immunotherapy is more effective in patients under 40 years of age (48); however, good responses were reported in individual case reports of patients older than 40 years (15).

\section{Anti-MAP1B/anti-PCA-2 antibody}

PCA2 antibody was first identified in a case series of ten patients in 2000, nine of whom had small cell lung carcinoma (SCLC). The neurological presentations included cerebellar ataxia, limbic encephalitis, Lambert-Eaton myasthenic syndrome, and neuropathy. The serum IgG binds to cytoplasm and dendrites of cerebellar Purkinje, neurons in the internal granular layer and dentate nucleus (16). Due to its different binding mode from PCA-1 (also known as anti- 
Yo-antibody) (5), it was initially named PCA-2.

PCA-2 antibody binds to PC dendrites and soma, but spares the PC nucleus. The molecular and granular layers were extensively stained, which was different from most other anti-PCs-antibodies. Antibody binding fluorescence is characterized by distinctive faint 'chickenwire pattern', which is different from that of anti-Yo and anti-Tr antibodies (16) . In addition, positive reactivity was observed in hippocampal neurons (especially in the CA1 area), cortex, and peripheral nerves. In 2017, Gadoth and colleagues identified MAP1B as the antigen of PCA-2. It is an intracellular protein with $270 \mathrm{kD}$ mass, which is an important component of the neurocytoskeleton protein (17). Because no commercial antigen-specific immunoassays are currently available, the detection has to be based on IHC in our lab. Because of the widespread distribution of MAP1B throughout the central and peripheral nervous systems, various neurologic symptoms were observed, ranging from ataxia, seizures, to cognitive decline, and neuropathy (8). Thirty percent of PCA2-positive patients present with cerebellar ataxia. Tumors were detected in approximately $80 \%$ of patients, of which $80 \%$ were SCLC. About half of them responded to immunotherapy, including corticosteroids, PLEX, and IVIG (8).

There are three cases of anti-PCA2-antibody in our project on Autoantibody Screening for the Diagnosis of ACA (14). All of them were children. They had significant manifestations of cerebellar ataxia, one of which also had peripheral neuropathy. Cranial MRI showed significant cerebellar atrophy. Mild pleocytosis in the CSF was seen in one patient and CSF-specific oligoclonal bands (OCBs) positive in two patients. No tumor was found in any of the patients. Similar to the reports of adults (14), these children did not respond well to immunotherapy, though their clinical phenotype was relatively homogeneous, cerebellar symptoms were prominent, with or without peripheral neuropathy. Patients with tumors were not found temporarily, and long-term follow-up is still needed to determine the prognosis.

\section{Anti-Homer-3 antibody}

Homer-3 protein is predominantly expressed on the dendritic spines of PCs (50) as well as in the cortex and CA2 and CA3 regions of the hippocampus. Outside the CNS, Homer-3 has been detected in the thymus and lungs. It is a scaffold protein that interacts with metabotropic glutamate receptor 1 (mGluR1) and inositol 1,4,5 triphosphate receptors, regulating calcium metabolism (51). IHC showed that PCs were stained with cytoplasm and the molecular layer was also bound, but less intensive (Figure 1C). Currently, some techniques are available for use in laboratory research, including a cell-based assay (CBA) employing HEK293 cells transfected with human Homer-3 (Euroimmun), a mixed phage display assay $(20,21)$. TBA was carried out simultaneously for verification in our laboratory.

To date, three patients have been reported, including one in our team in 2019 (22). They developed acute or subacute cerebellar ataxia at the age of 38-65 years. The main symptoms included vertigo, vomiting, unsteady gait, and dysmetria. One patient had papilledema and convulsions. CSF showed mild pleocytosis in two patients. There was no cerebellar atrophy in the early stage, but appeared at the later stage in two cases. No tumor was found in all three patients. Immunotherapy was partially effective (22).

\section{Anti-NCDN antibody}

NCDN is a $75-\mathrm{kDa}$ protein expressed in neurons in a somatodendritic distribution pattern (52). In the adult rodent brain, NCDN is highly expressed in the cerebellum, amygdala, and hippocampus (53). IFA screening revealed strong IgG1 reactivity in sera and CSF with PCs and cerebellar molecular and granular layers, which is also seen in the hippocampus. However, there was no reactivity in the control group. The exact pathogenic process of antiNCDN anybody is not known, but the interaction between NCDN and G-protein-coupled receptors was verified. The latter are associated with the regulation of long-term synaptic plasticity in the cerebellum and hippocampus. Therefore, anti-NCDN antibody may play a pathogenic role by changing the function of the G-protein-coupled receptor (54).

$\mathrm{NCDN}$-antibody-associated cerebellar ataxia has recently been recognized. Miske reported the first case series of three autoimmune ataxias related to anti-NCDN antibodies in adults in 2016 (18). Our team reported the second series in 2019 (19). TBA and CBA were simultaneously used to identify the anti-NCDN antibody. All six patients, including two children, mainly presented with cerebellar ataxia and no cerebra symptoms. CSF of the three cases exhibited mild pleocytosis. Cerebellar atrophy was seen in four cases. The antibody titer detected in serum was higher than CSF, and some patients had negative antibodies in the CSF. Tumor screening did not reveal an underlying malignant tumor in any of the cases for 27-120 months after symptom onset. 
Table 2 Differential diagnosis of ACA

\begin{tabular}{|c|c|c|c|c|c|}
\hline Metabolic & Infections & Hereditary & $\begin{array}{l}\text { Other autoimmune } \\
\text { disease }\end{array}$ & Nutrition/toxic & Others \\
\hline $\begin{array}{l}\text { Mitochondrial } \\
\text { disorders }\end{array}$ & $\begin{array}{l}\text { Viral (EBV, VZV, JCV, } \\
\text { prion, HIV) }\end{array}$ & Channelopathies & SLE & Drugs & Stoke \\
\hline $\begin{array}{l}\text { Amino acid/organic } \\
\text { acid metabolism } \\
\text { disorders: } \\
\text { MSUD, MMA }\end{array}$ & $\begin{array}{l}\text { Bacterial } \\
\text { (Streptococcus, } \\
\text { Tropheryma whipplei) }\end{array}$ & $\begin{array}{l}\text { Autosomal-dominant/ } \\
\text { recessive ataxias }\end{array}$ & Behcet's & Alcohol abuse & Trauma \\
\hline $\begin{array}{l}\text { Storage disease: } \\
\text { NPC }\end{array}$ & Mycoplasma & & $\begin{array}{l}\text { CNS demyelinating } \\
\text { diseases }\end{array}$ & $\begin{array}{l}\text { Vitamin deficiencies: } \\
\text { Wernicke } \\
\text { encephalopathy, others }\end{array}$ & $\begin{array}{l}\text { Posterior cranial } \\
\text { fossa tumor }\end{array}$ \\
\hline GLUT1-DS & $\begin{array}{l}\text { Others (syphilis, } \\
\text { tuberculosis, } \\
\text { borreliosis) }\end{array}$ & & & & $\begin{array}{l}\text { Endocrine } \\
\text { (hypothyroidism, } \\
\text { hypoparathyroidism) }\end{array}$ \\
\hline
\end{tabular}

ACA, autoimmune cerebellar ataxia; EBV, Epstein-Barr virus; VZV, Varicella-zoster virus; JCV, JC virus; SLE, systemic lupus erythematosus; MSUD, maple syrup urine disease; MMA, methylmalonic acidemia; NPC, Niemann-Pick disease type C; CNS, central nervous system; GLUTI-DS, glucose transporter type 1 deficiency syndrome.

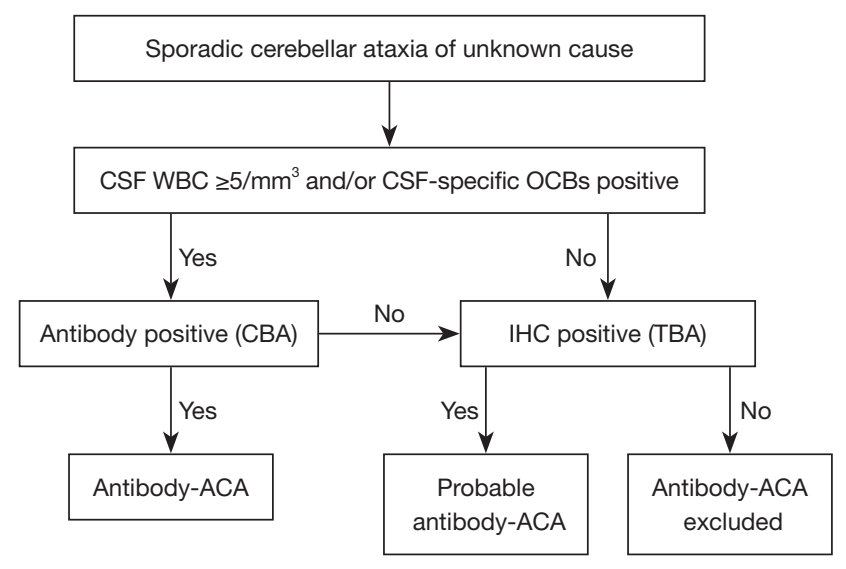

Figure 2 Diagnostic strategy for antibody associated ACA. CSF, cerebrospinal fluid; WBC, white blood cells; OCBs, oligoclonal bands; IHC, immunohistochemistry; CBA, cell-based assay; TBA, tissue-based assay; ACA, autoimmune cerebellar ataxia.

Immunotherapy is effective for some patients, especially for patients with relatively short duration.

\section{Diagnosis and differential diagnosis of ACA}

ACA is a new field in neuroimmunology. There are even many controversies and unknowns. So far, no consensus on the diagnostic criteria was formed. Confirmation of specific antibodies plays a vital role in the diagnosis. However, in terms of diagnostic technology, ACA related antibody detection methods are limited, especially in China, so that ACA is probably under-diagnosed. In this situation, for patients with sporadic cerebellar ataxia of unknown cause, after reasonably excluding other diseases (Table 2), CSF and/or serum TBA can be used as a more feasible screening method, especially for the anti-PCs antibody-related ACA, which has relatively distinct morphological characteristics in IHC.

Based on previous research in this field and our exploratory work, under the currently available experimental technology, we propose a diagnostic strategy for antibody-associated ACA (Figure 2). For unexplained sporadic cerebellar ataxia, if CSF pleocytosis [white blood cells (WBC) $\left.\geq 5 / \mathrm{mm}^{3}\right]$ and/or CSF-SOB-positivity are presented, CBA-positive patients can be diagnosed as "antibody-associated ACA". For patients without the abovementioned manifestations of CSF or CBA-negative patients, TBA screening procedures are performed. TBA-positive patients can be diagnosed as "probable antibody-associated ACA". After comprehensive consideration of the clinical information, immunotherapy can be started timely. If TBA is also negative, the ACA diagnosis is initially excluded and clinicians should reevaluate patients and follow-up for additional clues. It is suggested that continuous observation should be carried out for the patients mentioned above, and relevant laboratory indicators can be repeatedly checked if necessary.

Some points need to be emphasized. First, the ACA 
is mainly characterized by the cerebellum with or without brainstem syndrome. Some patients may show extracerebellar manifestations, for example, peripheral neuropathy, encephalopathy, seizures, sleep disturbance, dystonia, etc. There are some indications for ACA diagnosis, for example, occurrence in patients with tumors, onset or fluctuation after infection, and response to immunotherapy. Second, the premise of this diagnosis strategy is to reasonably exclude other diseases. As shown in Table 2, many etiologies are associated with cerebellar syndrome. It is important to carefully exclude similar diseases with detailed medical history, physical examination, and auxiliary examination. Genetic or metabolic diseases can be excluded by metabolic biochemistry and gene testing. Cranial MRI can identify a considerable part of CNS demyelinating diseases, stroke, and systemic autoimmune diseases. Traditional and advanced pathogen detection techniques such as CSF metagenomic nextgeneration sequencing provide support for excluding infectious diseases, especially some rare infections such as progressive multifocal leukoencephalopathy (PML), Whipple's disease, etc. With further understanding of the ACA and the advancement of diagnostic technology, ACA diagnosis strategy will definitely be more rigorous and scientific. Close combination of clinical information and laboratory data is an important basis for ACA diagnosis.

\section{Conclusions and perspectives}

Anti-PC antibodies mainly react with antigens in the cytoplasm and dendrites of PCs, so they have certain similarities in the morphology of IHC and are often discussed together. The properties of some anti-PCs antibodies reported are shown in Table 2 (23-38). In addition, we also recognize that there are some unknown antibodies associated with ACA. Because most of the antibody related cases are very few, the phenotype is not very clear, which remains to be further studied. In 2018, Mitoma elaborated the concept of "Cerebellum Reserve". He proposed "Time is Cerebellum" as a principle in the management of patients with cerebellar diseases and suggested that the treatment should be carried out as early as possible in the reversible stage to avoid cerebellar degeneration (55). At present, there is no consensus on disease classification, diagnosis, treatment, and other aspects of the disease. However, the rapid evolution of antibody detection technology provides the possibility for early and timely diagnosis. Anti-PCs-antibodies play an important role in the study of ACA. Our previous exploratory work also confirms that as an important cause of treatable ataxia, ACA deserves much attention and further study. Researches on ACA will be the frontier of Neurology in the next 10 years.

\section{Acknowledgments}

Funding: None.

\section{Footnote}

Provenance and Peer Review: This article was commissioned by the Guest Editors (Hai-Feng Li and Xiangjun Chen) for the series "Laboratory Investigations in Neuroimmunological Diseases and Their Clinical Significance" published in Annals of Translational Medicine. The article has undergone external peer review.

Conflicts of Interest: All authors have completed the ICMJE uniform disclosure form (available at https://atm.amegroups. com/article/view/10.21037/atm-20-2187/coif). The series "Laboratory Investigations in Neuroimmunological Diseases and Their Clinical Significance" was commissioned by the editorial office without any funding or sponsorship. The authors have no other conflicts of interest to declare.

Ethical Statement: The authors are accountable for all aspects of the work in ensuring that questions related to the accuracy or integrity of any part of the work are appropriately investigated and resolved.

Open Access Statement: This is an Open Access article distributed in accordance with the Creative Commons Attribution-NonCommercial-NoDerivs 4.0 International License (CC BY-NC-ND 4.0), which permits the noncommercial replication and distribution of the article with the strict proviso that no changes or edits are made and the original work is properly cited (including links to both the formal publication through the relevant DOI and the license). See: https://creativecommons.org/licenses/by-nc-nd/4.0/.

\section{References}

1. Mitoma H, Adhikari K, Aeschlimann D, et al. Consensus Paper: Neuroimmune Mechanisms of Cerebellar Ataxias. Cerebellum 2016;15:213-32.

2. Hadjivassiliou M, Martindale J, Shanmugarajah P, et 
al. Causes of progressive cerebellar ataxia: prospective evaluation of 1500 patients. J Neurol Neurosurg Psychiatry 2017;88:301-9.

3. Lancaster E, Dalmau J. Neuronal autoantigens-pathogenesis, associated disorders and antibody testing. Nat Rev Neurol 2012;8:380-90.

4. Jarius S, Wildemann B. 'Medusa head ataxia': the expanding spectrum of Purkinje cell antibodies in autoimmune cerebellar ataxia. Part 1: Anti-mGluR1, anti-Homer-3, anti-Sj/ITPR1 and anti-CARP VIII. J Neuroinflammation 2015;12:166.

5. Greenlee JE, Brashear HR. Antibodies to cerebellar Purkinje cells in patients with paraneoplastic cerebellar degeneration and ovarian carcinoma. Ann Neurol 1983;14:609-13.

6. Trotter JL, Hendin BA, Osterland CK. Cerebellar degeneration with Hodgkin disease. An immunological study. Arch Neurol 1976;33:660-1.

7. Jarius S, Wildemann B. 'Medusa head ataxia': the expanding spectrum of Purkinje cell antibodies in autoimmune cerebellar ataxia. Part 2: Anti-PKC-gamma, anti-GluR-delta2, anti-Ca/ARHGAP26 and anti-VGCC. J Neuroinflammation 2015;12:167.

8. Jarius S, Wildemann B. 'Medusa head ataxia': the expanding spectrum of Purkinje cell antibodies in autoimmune cerebellar ataxia. Part 3: Anti-Yo/CDR2, anti-Nb/AP3B2, PCA-2, anti-Tr/DNER, other antibodies, diagnostic pitfalls, summary and outlook. J Neuroinflammation 2015;12:168.

9. Goto A, Kusumi M, Wakutani Y, et al. Anti-Yo antibody associated paraneoplastic cerebellar degeneration with gastric adenocarcinoma in a male patient: a case report. Rinsho Shinkeigaku 2006;46:144-7.

10. Joubert B, Rostásy K, Honnorat J. Immune-mediated ataxias. Handb Clin Neurol 2018;155:313-32.

11. Venkatraman A, Opal P. Paraneoplastic cerebellar degeneration with anti-Yo antibodies - a review. Ann Clin Transl Neurol 2016;3:655-63.

12. Peterson K, Rosenblum MK, Kotanides H, et al. Paraneoplastic cerebellar degeneration. I. A clinical analysis of 55 anti-Yo antibody-positive patients. Neurology 1992;42:1931-7.

13. Graus F, Dalmau J, Valldeoriola F, et al. Immunological characterization of a neuronal antibody (anti-Tr) associated with paraneoplastic cerebellar degeneration and Hodgkin's disease. J Neuroimmunol 1997;74:55-61.

14. Haitao R, Xu X, Guan H, et al. Autoantibody screening for the diagnosis of autoimmune cerebellitis. Chin J Neurol
2019;52:304-9.

15. Han F, Ren H, Tang M, et al. Clinical Reasoning: A 47-year-old man with rapidly progressive ataxia and vitiligo. Neurology 2020;94:e1664-9.

16. Vernino S, Lennon VA. New Purkinje cell antibody (PCA-2): marker of lung cancer-related neurological autoimmunity. Ann Neurol 2000;47:297-305.

17. Gadoth A, Kryzer TJ, Fryer J, et al. Microtubuleassociated protein 1B: Novel paraneoplastic biomarker. Ann Neurol 2017;81:266-77.

18. Miske R, Gross CC, Scharf M, et al. Neurochondrin is a neuronal target antigen in autoimmune cerebellar degeneration. Neurol Neuroimmunol Neuroinflamm 2017;4:e307.

19. Weihua Z, Haitao R, Fang F, et al. Neurochondrin Antibody Serum Positivity in Three Cases of Autoimmune Cerebellar Ataxia. Cerebellum 2019;18:1137-42.

20. Zuliani L, Sabater L, Saiz A, et al. Homer 3 autoimmunity in subacute idiopathic cerebellar ataxia. Neurology 2007;68:239-40.

21. Höftberger R, Sabater L, Ortega A, et al. Patient with homer-3 antibodies and cerebellitis. JAMA Neurol 2013;70:506-9.

22. Xu X, Ren H, Li L, et al. Anti-Homer-3 antibody associated cerebellar ataxia: A rare case report and literature review. J Neuroimmunol 2019;330:155-8.

23. Darnell RB, Furneaux HM, Posner JB. Antiserum from a patient with cerebellar degeneration identifies a novel protein in Purkinje cells, cortical neurons, and neuroectodermal tumors. J Neurosci 1991;11:1224-30.

24. Honorat JA, Lopez-Chiriboga AS, Kryzer TJ, et al. Autoimmune gait disturbance accompanying adaptor protein-3B2-IgG. Neurology 2019;93:e954-63.

25. Sabater L, Bataller L, Carpentier AF, et al. Protein kinase Cgamma autoimmunity in paraneoplastic cerebellar degeneration and non-small-cell lung cancer. J Neurol Neurosurg Psychiatry 2006;77:1359-62.

26. Höftberger R, Kovacs GG, Sabater L, et al. Protein kinase $\mathrm{C} \gamma$ antibodies and paraneoplastic cerebellar degeneration. J Neuroimmunol 2013;256:91-3.

27. Ren H, Zhao D, Xu X, et al. Paraneoplastic cerebellar degeneration associated with anti-protein kinase Cgamma antibodies in a Chinese patient. J Neuroimmunol 2020;350:577408.

28. Iorio R, Damato V, Mirabella M, et al. Cerebellar degeneration associated with mGluR1 autoantibodies as a paraneoplastic manifestation of prostate adenocarcinoma. J Neuroimmunol 2013;263:155-8. 
29. Lopez-Chiriboga AS, Komorowski L, Kümpfel T, et al. Metabotropic glutamate receptor type 1 autoimmunity: Clinical features and treatment outcomes. Neurology 2016;86:1009-13.

30. Yoshikura N, Kimura A, Fukata M, et al. Long-term clinical follow-up of a patient with non-paraneoplastic cerebellar ataxia associated with anti-mGluR1 autoantibodies. J Neuroimmunol 2018;319:63-7.

31. Jarius S, Scharf M, Begemann N, et al. Antibodies to the inositol 1,4,5-trisphosphate receptor type 1 (ITPR1) in cerebellar ataxia. J Neuroinflammation 2014;11:206.

32. Berzero G, Hacohen Y, Komorowski L, et al. Paraneoplastic cerebellar degeneration associated with anti-ITPR1 antibodies. Neurol Neuroimmunol Neuroinflamm 2017;4:e326.

33. Alfugham N, Gadoth A, Lennon VA, et al. ITPR1 autoimmunity: Frequency, neurologic phenotype, and cancer association. Neurol Neuroimmunol Neuroinflamm 2018; 5:e418.

34. Wallwitz U, Brock S, Schunck A, et al. From dizziness to severe ataxia and dysarthria: New cases of anti-Ca/ ARHGAP26 autoantibody-associated cerebellar ataxia suggest a broad clinical spectrum. J Neuroimmunol 2017;309:77-81.

35. Jarius S, Wandinger KP, Horn S, et al. A new Purkinje cell antibody (anti-Ca) associated with subacute cerebellar ataxia: immunological characterization. J Neuroinflammation 2010;7:21.

36. Höftberger R, Sabater L, Velasco F, et al. Carbonic anhydrase-related protein VIII antibodies and paraneoplastic cerebellar degeneration. Neuropathol Appl Neurobiol 2014;40:650-3.

37. Bataller L, Sabater L, Saiz A, et al. Carbonic anhydraserelated protein VIII: autoantigen in paraneoplastic cerebellar degeneration. Ann Neurol 2004;56:575-9.

38. Do LD, Gupton SL, Tanji K, et al. TRIM9 and TRIM67 Are New Targets in Paraneoplastic Cerebellar Degeneration. Cerebellum 2019;18:245-54.

39. Sakai K, Mitchell DJ, Tsukamoto T, et al. Isolation of a complementary DNA clone encoding an autoantigen recognized by an anti-neuronal cell antibody from a patient with paraneoplastic cerebellar degeneration. Ann Neurol 1990;28:692-8.

40. Furneaux HM, Dropcho EJ, Barbut D, et al. Characterization of a cDNA encoding a 34-kDa Purkinje neuron protein recognized by sera from patients with paraneoplastic cerebellar degeneration. Proc Natl Acad Sci U S A 1989;86:2873-7.
41. Altermatt HJ, Rodriguez M, Scheithauer BW, et al. Paraneoplastic anti-Purkinje and type I anti-neuronal nuclear autoantibodies bind selectively to central, peripheral, and autonomic nervous system cells. Lab Invest 1991;65:412-20.

42. de Graaff E, Maat P, Hulsenboom E, et al. Identification of delta/notch-like epidermal growth factor-related receptor as the $\mathrm{Tr}$ antigen in paraneoplastic cerebellar degeneration. Ann Neurol 2012;71:815-24.

43. Eiraku M, Hirata Y, Takeshima H, et al. Delta/notch-like epidermal growth factor (EGF)-related receptor, a novel EGF-like repeat-containing protein targeted to dendrites of developing and adult central nervous system neurons. J Biol Chem 2002;277:25400-7.

44. Graus F, Gultekin SH, Ferrer I, et al. Localization of the neuronal antigen recognized by anti-Tr antibodies from patients with paraneoplastic cerebellar degeneration and Hodgkin's disease in the rat nervous system. Acta Neuropathol 1998;96:1-7.

45. Nishizumi H, Komiyama T, Miyabayashi T, et al. BET, a novel neuronal transmembrane protein with multiple EGF-like motifs. Neuroreport 2002;13:909-15.

46. Greene M, Lai Y, Baella N, et al. Antibodies to Delta/ notch-like epidermal growth factor-related receptor in patients with anti-Tr, paraneoplastic cerebellar degeneration, and Hodgkin lymphoma. JAMA Neurol 2014;71:1003-8.

47. Probst C, Komorowski L, de Graaff E, et al. Standardized test for anti-Tr/DNER in patients with paraneoplastic cerebellar degeneration. Neurol Neuroimmunol Neuroinflamm 2015;2:e68.

48. Bernal F, Shams'ili S, Rojas I, et al. Anti-Tr antibodies as markers of paraneoplastic cerebellar degeneration and Hodgkin's disease. Neurology 2003;60:230-4.

49. Avramova BE, Hristova T, Yordanova M, et al. Cerebellar Degeneration as a Rare Paraneoplastic Syndrome in a Child With Hodgkin Lymphoma. J Pediatr Hematol Oncol 2016;38:470-2.

50. Shiraishi Y, Mizutani A, Yuasa S, et al. Differential expression of Homer family proteins in the developing mouse brain. J Comp Neurol 2004;473:582-99.

51. Beqollari D, Kammermeier PJ. The interaction between mGluR1 and the calcium channel Cav2.1 preserves coupling in the presence of long Homer proteins. Neuropharmacology 2013;66:302-10.

52. Wang H, Nong Y, Bazan F, et al. Norbin: A promising central nervous system regulator. Commun Integr Biol 2010;3:487-90. 
53. Wang H, Westin L, Nong Y, et al. Norbin is an endogenous regulator of metabotropic glutamate receptor 5 signaling. Science 2009;326:1554-7.

54. Istvánffy R, Vogt Weisenhorn DM, Floss T, et al. Expression of neurochondrin in the developing and adult

Cite this article as: Zhang W, Ren H, Ren X, Fang F, Guan H. Autoimmune cerebellar ataxia associated with antiPurkinje cells antibodies: the next frontier of neuroimmunology. Ann Transl Med 2023;11(7):285. doi: 10.21037/atm-20-2187 mouse brain. Dev Genes Evol 2004;214:206-9.

55. Mitoma H, Manto M, Hampe CS. Time Is Cerebellum. Cerebellum 2018;17:387-91. 